ISSN 2447-9071

doi https://doi.org/10.36414/rbmc.v6i16.65

Contato para correspondência: Hermínio Maurício da Rocha Sobrinho

E-mail:

herminio.sobrinho@gmail.com

Conflito de interesse: Não

Financiamento: Recursos próprios

Recebido: $16 / 11 / 2020$

Aprovado: 29/11/2020

\section{Os benefícios da limpeza de pele no tratamento coadjuvante da acne vulgar}

\section{The benefits of skin cleansing in the adjunctive treatment of acne vulgaris}

Maria Cleonice de Jesus Silva', Flávia Martins Nascente ${ }^{1,2}$, Cláudia Maria Duque de Souza', Alessandra Marques Cardoso ${ }^{1,2,3}$, Luciana de Lara Pontes Ferreira ${ }^{4}$, Hermínio Maurício da Rocha Sobrinho ${ }^{1,4}$

\author{
'Pontifícia Universidade Católica de Goiás - PUC Goiás \\ ${ }^{2}$ Faculdade da Polícia Militar - FPM \\ ${ }^{3}$ Secretaria de Estado da Saúde de Goiás - SES-GO \\ ${ }^{4}$ Universidade Estadual de Goiás - UEG
}

\begin{abstract}
Resumo
Aacnevulgaréuma condição dermatológica comum que pode causarinflamaçãoecicatrizes graves, quesurgem como uma sequela desta patologia. Otratamento da acneenvolve mudanças de hábitos diários como a lavagem facial, higienização adequada da pele, hidratação, proteção, prevenção de danos cutâneose aplicação de cosméticos tópicos. Oobjetivo destetrabalho foiapresentaros principais benefícios dos procedimentos de limpeza de peleeextração de comedões no tratamento coadjuvante da acnevulgar. Trata-se de uma revisão bibliográfica narrativa. Estudos demonstraram que alimpeza de pele écapaz de reduzir a sujidade e oleosidade cutânea, eliminar células mortas, equilibrar o $\mathrm{pH}$ da pelee diminuir a contaminação pormicrorganismos capazes de provocar infecçãonos folículos pilosos. O protocolo de uma limpeza de pele profissional inclui a extração de comedões e deve ser específico para cada indivíduo, para a obtenção da satisfação e eficiência no tratamento. Recomenda-se que a limpezafacial deveser efetuada umavezpordia, comagente delimpezaajustadoao tipo depele, como preparação para a aplicação dos tratamentos posteriores. Devido ao efeito irritativo do tratamento farmacológico da acne vulgar, deve-se usar cremes ou emulsões sem óleo, sendo fundamental evitar a manipulação das lesões.
\end{abstract}

Palavras-Chave: Limpeza de pele, Lavagem facial, Acne vulgar, Comedões, Cosméticos.

\begin{abstract}
Acne vulgaris is a common dermatological condition that can cause inflammation and severe scarring, which appear as a sequel to this pathology. Acne treatment involves good lifelong skin care practices such as facial washing, cleanse correctly, hydration, protection, preventing skin damage and applying topical cosmetics. The objective of this work was to present the main benefits of skin cleansing and comedone extraction procedures in the coadjuvant treatment of acne vulgaris. This is a narrative bibliographic review. Studies have shown that skin cleansing is able to reduce dirt and oil from the skin, eliminate dead cells, balance skin $\mathrm{pH}$ and decrease contamination by microorganisms capable of causing infection in hair follicles. The professional protocol skin cleansing includes the extraction of comedones and must be specific for each individual to obtain satisfaction and efficiency in the treatment. It is recommended that facial cleansing should be carried out once a day, with a cleaning agent adjusted to the skin type, in preparation for the application of subsequent treatments. Due to the irritating effect of pharmacological treatment of acne vulgaris, creams or emulsions without oil should be used, and it is essential avoid manipulation of the lesions.
\end{abstract}

Keywords: Skin cleansing; Facial cleaning; Acne vulgaris; Comedones; Cosmetics. 


\section{Introdução}

O ser humano, de forma geral, está sujeito à ações do meio ambiente, essas ações interferem na saúde da pele. Agentes ambientais tais como a umidade, vento, sol, poluição, colocam a pele em risco podendo causar danos cutâneos, fotoenvelhecimento e até doenças dermatológicas ${ }^{1,2}$. Os cuidados com a pele são essenciais e podem ser inicializados desde a infância ou adolescência, as atenções maiores devem ser dadas principalmente ao rosto e as mãos, pois são essas partes que ficam mais expostas aos agentes ambientais ${ }^{3}$.

Embora a acne vulgar não seja comumente considerada uma afecção cutânea grave, pode ser muito incômoda e, dependendo do grau, causa alterações estéticas que podem ter impacto social e psicológico na qualidade de vida do indivíduo 4 .

Uma necessidade de grande parte da população mundial é o controle das lesões provenientes da acne vulgar. Isto pode ser realizado por meio da limpeza adequada da pele e extração de comedões, conhecidos como "cravos", que sendo feito por profissional habilitado e experiente, promove melhoria imediata no aspecto da pele e acentua a satisfação do paciente, pois reduz as lesões inflamatórias da acne e o grau de comprometimento clínico ${ }^{2-6}$.

Normalmente, antes de diversos tipos de procedimentos estéticos faciais e corporais a limpeza de pele é indicada para se evitar contaminações, infecções e até possíveis efeitos adversos $^{1,7}$. A limpeza de pele profissional é um procedimento estético que pode ser utilizado em qualquer fototipo cutâneo para eliminar cravos e espinhas, hidratar a pele, promover renovação celular, remover o acúmulo de impurezas e radicais livres, eliminação de células mortas e sebo da pele. Recentemente, o interesse em tratamentos para acne envolvendo a modificação de atividades diárias, como a limpeza de pele e lavagem facial, tem demonstrado benefícios no tratamento coadjuvante da acne vulgar ${ }^{2-7}$.

Este trabalho tem por objetivo abordar os principais benefícios da higienização da pele com extração de comedões no tratamento estético da acne vulgar, destacando-os cuidados durante os procedimentos e sugerindo medidas de prevenção para a acne.

\section{Métodos}

Trata-se de uma revisão bibliográfica narrativa. Foram utilizadas as bases de dados eletrônicas Pubmed (US National Library of Medicine), Portal de Periódicos da Capes e o Google Acadêmico para busca dos trabalhos em língua portuguesa e inglesa, com o uso de Descritores em Ciências da Saúde: limpeza de pele, limpeza facial, lavagem, comedões, acne vulgar, cosméticos. O recorte temporal da pesquisa foi do ano de 2004 ao ano de 2019. Foram incluídos no estudo apenas estudos cujos textos completos estavam disponíveis nas plataformas virtuais utilizadas e que abordavam os benefícios da limpeza de pele e extração de comedões no controle e prevenção da acne vulgar. Foram excluídos estudos duplicados, aqueles publicados antes do ano de 2004, os que não estavam disponíveis na íntegra nas bases de dados virtuais utilizadas e os estudos cujos conteúdos não estavam relacionados aos objetivos propostos. Um total de 72 estudos foram encontrados, entretanto, apenas 16 estudos obedeceram aos critérios de inclusão estabelecidos.

\section{Resultados e Discussão}

\section{A Pele}

A pele, além de ser o primeiro órgão de defesa do organismo contra os agentes agressores teciduais do meio externo, possui papéis importantes na imunidade e percepção de estímulos, cujas complexidades e higidez contribuem para a manutenção da homeostase do organismo. Tais funções propriedades, no entanto, só são desempenhadas com excelência se o tecido tegumentar estiver em condições normais e plenas de funcionamento e cuidado ${ }^{5,6}$.

A pele é o maior órgão do corpo humano, que tem como funções proteger do ambiente externo, controlar a perda de água, regular a temperatura corporal e também tem função sensorial. É composta de 3 camadas teciduais principais: a epiderme, a derme e o tecido subcutâneo e os anexos cutâneos: folículos pilosos, glândulas sebáceas e glândulas sudoríparas. Cada camada possui características e funções específicas ${ }^{5,6}$.

Quanto ao grau de oleosidade, a pele pode ser normal ou eudérmica, seca ou alipídica, oleosa ou lipídica e mista. A pele normal tem textura saudável e aveludada, produzindo gordura em quantidade adequada, sem excesso de brilho ou ressecamento. Geralmente, a pele normal apresenta poros pequenos e pouco visíveis. A perda de água em excesso caracteriza a pele seca, que normalmente tem poros poucos visíveis, pouca luminosidade sendo mais propensa à descamação e inflamação, além de apresentar maior tendência ao aparecimento de pequenas linhas e fissuras. A pele oleosa tem aspecto mais brilhante e espesso, por causa da produção de sebo maior do que o normal. A pele oleosa apresenta poros dilatados $e$ maior tendência à formação de acne, de cravos e de espinhas. $A$ pele mista é o tipo de pele mais frequente. Apresenta aspecto oleoso e poros dilatados na "zona T" (testa, nariz e queixo), podendo apresentar acne nesta região e seco nas bochechas e extremidades. Mas, apesar dessa divisão, todas as peles têm 
uma concentração maior de glândulas sebáceas na zona T do que nas regiões laterais da face. Assim, todas as peles secas são menos secas na região médio-facial, o que também ocorre com as peles normais e oleosas ${ }^{3,5,8}$.

Cada pessoa tem seu próprio metabolismo, que varia de acordo com a herança genética, os hábitos alimentares, os ambientes em que vive, entre outros fatores. A pele reage a essas condições biológicas e climáticas e se constitui de formas distintas: pode ser seca, oleosa, normal, acneica, ou sensível ${ }^{3,5,7,8}$.

\section{Acne Vulgar}

A acne é uma doença crônica que atinge aproximadamente $85 \%$ dos adolescentes manifestando-se em diferentes partes do corpo e em intensidade variada podendo provocar sequelas estéticas corporais. Trata-se de uma doença inflamatória da unidade pilossebácea da pele que se manifesta, inicialmente, por comedões abertos e/ou fechados, podendo apresentar também, pápulas, pústulas e lesões nodulocísticas, com grau variável de inflamações e cicatrizes ${ }^{9}$.

Acne vulgar é determinada pela ação de múltiplos fatores. Ao ocorrer um desequilíbrio na quantidade ou na qualidade da secreção sebácea, dá-se o episódio da acne, que pode sofrer influência por agentes externos como: períodos de tensão ou mudanças de estilos de vida e agentes internos como genética e alterações endócrinas ${ }^{8,9}$.

Estudos evidenciam que a bactéria Propioniobacterium acnes é um dos agentes etiológicos responsável pela acne. Se prolifera devido a alterações na composição e na quantidade da secreção sebácea, auxiliando na alteração do ducto glandular, favorecendo o processo de ruptura folicular. Com a ruptura da parede da glândula e a saída da queratina, restos pilosos e lipídios provenientes do comedão, induzem a uma reação inflamatória, contribuindo para o processo patológico ${ }^{10}$.

A acne é constituída por um conjunto de lesões, as quais, isoladas ou em conjunto, definem o tipo e gravidade da acne. Do ponto de vista clínico a acne classifica-se em não inflamatória e inflamatória, de acordo o tipo de lesão predominante. Quando somente observamos a presença de comedões chama-se acne não inflamatória, envolvendo comedões abertos (conhecidos como cravos) e comedões fechados, com seborreia presente. A partir deste estágio aparecem pápulas, nódulos, cistos. De acordo com o tipo de acne, estas se subdividem em graus $^{10}$ :

Acne Grau I: Conhecida como acne comedogênica, caracteriza-se pela presença de comedões, porém, a existência de algumas pápulas e raras pústulas foliculares. Ainda permite considerar o quadro grau I.
Acne Grau II: Chamada de acne papulopustulosa, caracteriza-se pela presença de comedões abertos; de pápulas com ou sem eritema inflamatório e de pústulas ${ }^{10}$.

Acne Grau III: Conhecida como nódulo-cística. Há comedões abertos, pápulas, pústulas e seborreia. Devido a ruptura da parede folicular, há reação inflamatória aos corneócitos e bactérias. Essa reação atinge desde a profundidade do folículo até o pelo, formando nódulos furunculoides ${ }^{10}$.

Acne Grau IV: Conhecida como acne conglobata, constitui forma grave em quadro anterior se associam nódulos purulentos, numerosos e grandes, formando abcessos e fístulas que drenam pus. As lesões de acne se subdividem em pápulas lesão palpável, rosada ou avermelhada pústulas evolui da lesão anterior aparecendo exsudato no seu conteúdo; nódulo - lesão sólida e elevada, é situada numa zona da derme mais que a pápula e o cisto, nódulo elástico, no aderente as estruturas subjacentes, que facilmente inflama e sutura. Localiza-se abaixo da camada basal, da qual resulta por regra, em cicatriz ${ }^{3,10}$.

Os comedões podem ser de dois tipos: comedões abertos e comedões fechados. O comedão fechado (cravo branco) é caracterizado por elevação cutânea de cor esbranquiçada ou amarelada, sendo mais visível quando a pele é esticada ou distendida. O comedão aberto (cravo preto), caracteriza-se por ser uma lesão ligeiramente elevada, visível, possuindo um ponto acastanhado ou negro, que pode atingir $5 \mathrm{~mm}$ de diâmetro ${ }^{3,6,10}$.

\section{Higienização da Pele}

A higiene da pele é de suma importância não só no âmbito de beleza, mas como também no que se diz respeito à saúde corporal. O processo diário de limpeza de pele deve ser realizado com produtos cosméticos adequados variando de acordo com cada tipo de pele. A limpeza contribui para a remoção dos agentes externos, secreções cutâneas naturais e micro-organismos ${ }^{5-7}$.

A limpeza de pele é um procedimento que visa remover cravos, espinhas, células mortas e outras impurezas da pele, para deixá-la com um aspecto mais saudável e juvenil. O procedimento deve ser realizado por profissionais especializados e a maneira de realiza-la varia de acordo com o tipo de pele (normal, oleosa e seca) ${ }^{5-7}$.

A higienização cutânea é um relevante cuidado inicial à acne vulgar, sendo sempre eficiente, exceto se exagerada, e visa à redução da seborreia. A limpeza de pele é um procedimento que visa remover cravos, espinhas, células mortas 
e outras impurezas da pele, para deixá-la com um aspecto mais saudável e juvenil ${ }^{5-8}$.

\section{Preparo da pele}

Para uma adequada e eficiente higienização é necessário realizar uma assepsia da pele, remover maquiagem, células mortas, secreções sebáceas e impurezas utilizando-se cosméticos adequados para estas funções s $^{7,11}$.

\section{Protocolo de Limpeza de pele profissional}

Antes de realizar qualquer procedimento estético convém ressaltar a importância do uso adequado dos Equipamentos de Proteção Individual (EPIs) pelo profissional (jaleco, luvas, toucas, máscara, etc) e pelo cliente e, ainda, a execução da avaliação clínica facial para verificação das particularidades de cada tipo de pele. $O$ protocolo de uma limpeza de pele profunda inclui a extração de comedões e deve ser específico para cada indivíduo para obter satisfação e eficiência no tratamento. A higienização profunda da pele consiste em retirar as sujidades superficiais e profundas, remover a oleosidade, extrair os comedões, além de retirar os conteúdos cutâneos que obstruem os folículos pilossebáceos que levam a afecções inestéticas como pápulas e pústulas ${ }^{5,6,11}$. As etapas da limpeza de pele profissional estão representadas na figura 1, a seguir.

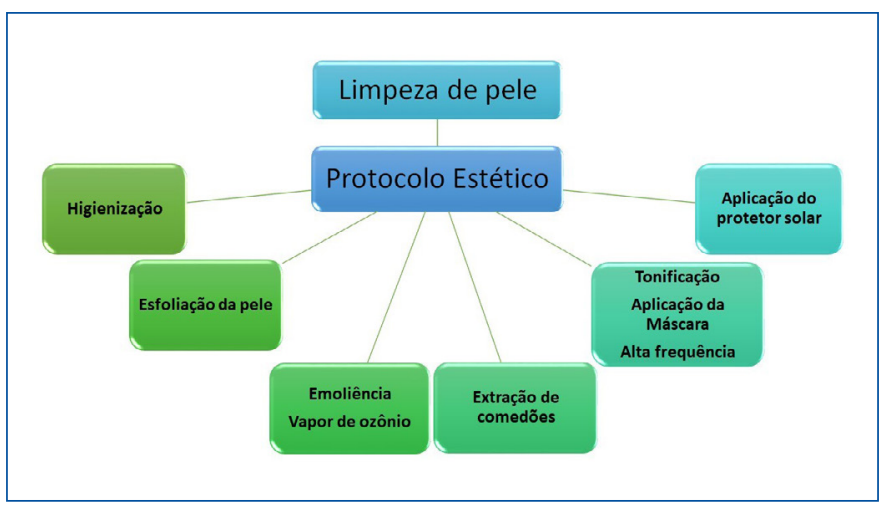

Figura 1. Fluxograma sobre as etapas do procedimento de limpeza de pele profissional.

\section{Higienização da pele}

O processo de higienização superficial da pele envolve a assepsia cutânea diária para remover células mortas, maquilagem, secreções sebáceas e impurezas. Neste processo a água é muito utilizada associada a sabões e detergentes que tem a função de emulsificar os ácidos graxos da pele, de preferência os sabonetes líquidos e cremosos, elaborados com tensoativos suaves e de baixa irritação cutânea. São incorporados a formu- lação dos sabonetes produtos que conferem caráter emoliente. Para este fim são utilizados Leites ou loções de limpeza; e géis de limpeza e soluções hidroalcóolicas ${ }^{5-7,11}$.

A higienização superficial da pele pode ser realizada com auxílio de sabonete, emulsão ou gel de limpeza para remoção das sujidades superficiais como poluição, suor e maquiagem. A limpeza profunda de pele deve ser realizada respeitando-se o ciclo de renovação celular a cada 28 dias $^{5-7,11}$.

\section{Esfoliação da Pele}

A esfoliação é o processo de remoção de células mortas da camada córnea da pele. A esfoliação é responsável por estimular o desenvolvimento de uma pele com brilho, maciez e viço. Pode ser usada por todos os tipos de pele, desde que se tenha o cuidado de não esfregar com muita intensidade, pois pode agredir as peles mais secas e sensíveis ${ }^{11}$. Os tipos de esfoliação da pele são:

Física/Mecânica: Atua por atrito. Retira as células mortas a partir do atrito promovido por pequenas partículas presentes em um creme esfoliante com a pele. Deve sempre ser feita de forma gentil, já que se empregarmos muita força, podemos acabar sensibilizando a pele. Há também peelings físicos em que são usados aparelhos de microdermoabrasão por fluxo de cristais ou lixas de pontas de diamantes.

Química: É feita com substâncias químicas, como a aplicação dos Alfa-hidroxiácidos (AHA) com pinceis específicos. Neste caso, não se esfrega o produto. Apenas aplica-se na pele, onde permanece por tempo variado em cada caso. É uma esfoliação mais intensa, por isso exige cuidados após a aplicação. Na esfoliação química, o produto faz com que as células mortas se desprendam, deixando a "pele nova" com mais brilho e uma textura mais macia (FASIH, 2016).

Enzimática/Biológica: Utilizam enzimas para eliminar o acúmulo de células mortas da superfície da pele. Podem ser obtidas de compostos naturais (biológicos), mas também podem ser sintéticas. No caso da biológica, ela utiliza enzimas provenientes da natureza - como a papaína (do mamão), bromelina (do abacaxi) ou a enzima da romã, que quebram proteínas e lipídeos na camada mais superficial da pele, ajudando na remoção das células mortas e deixando-a mais fina, uniforme e viçosa. Costuma ser bem tolerada até por peles mais sensíveis ${ }^{8,11,13}$.

\section{Emoliência}

Com a pele limpa inicia-se a emoliência dos comedões e dilatação dos poros dos folículos pilosos, aplicando por exem- 
plo, máscaras térmicas, vapor de ozônio, solução emoliente de trietanolamina a $10 \%$ ou cremes emolientes, que tem a função de facilitar o processo de extração. Umedeça os algodões com o produto e deixe agir sobre a pele por aproximadamente 10 minutos. Vá retirando os algodões região por região conforme você for fazendo a extração $0^{8,11,13}$.

\section{Extração de Comedões}

A forma de extração mais comumente realizada é a extração manual com as pontas dos dedos envoltos em algodão ou gaze, ressaltando-se o uso de luvas de procedimento pelo profissional e demais EPIs necessários. A força é exercida em 2 pontos até que o comedão seja removido completamente ${ }^{8,11,13}$.

Consiste na etapa mais longa da limpeza, onde são retirados os cravos (comedões). Pode ser realizada utilizando-se aparelhos de sucção, cureta ou manualmente, neste último método o profissional utiliza algodão entre os dedos e a face, para que não haja contato direto com a pele do paciente ao "espremer", evitando machucar o local que está sendo manipulado, e ocasionando o mínimo de dor possível. Para os cravos mais resistentes e retirada de milliuns usa-se uma microagulha para romper a pele. A extração deve ser realizada com técnicas corretas de manipulação, cuidadosamente e com delicadeza, para que o paciente não tenha dor ou incômodo. Pode ser utilizado também anestésico tópico para pacientes mais sensíveis. Não deve retirar durante esse processo as espinhas, para não haver contaminação com a secreção da mesma para outros locais do rosto, ou aumento do processo inflamatório da espinha, podendo até causar lesões cicatriciais. A remoção dos comedões promove a melhoria imediata e acentua a satisfação do paciente, pois a extração com princípio de antissepsia reduz o grau de comprometimento clínico da acne. Atualmente a desvantagem evidente, é que a extração da forma mais comumente utilizada, através da compressão manual da pele com os dedos, pode proporcionar danos na pele $e^{8,11,13}$.

\section{Tonificação da pele}

Antes de todos procedimentos de limpeza da pele devemos colocar uma solução tônica no rosto ou na região a ser tonificada. Os tônicos apresentam as funções de limpar a pele profundamente, melhoram a microcirculação local, preparam a pele para receber a hidratação, regulam o $\mathrm{pH}$ natural da pele, eliminam os resíduos acumulados nos poros dos folículos pilosos, suavizam, acalmam e refrescam a pele $\mathrm{e}^{8,11,13}$.

\section{Alta Frequência}

A Alta frequência é uma técnica em que se utilizam vários modelos de eletrodos de vidro com uma corrente alternada de frequência alta, que ao passar por esses eletrodos, no seu interior existe um gás com propriedades físico-químicas que facilita a transmissão da alta voltagem para o outro extremo do eletrodo, esses gases podem ser: argônio, neônio ou xênon, o meio condutor entre a bobina e o cliente, ioniza as moléculas deste gás, produzindo um campo eletromagnético que produz ozônio, na parte externa do vidro. É aplicada na superfície da pele e apresenta características descongestionantes cutâneas, bactericida e cicatrizantes $5^{8,11,13}$.

\section{Aplicação de Máscaras}

A aplicação da máscara deve ser feita após a aplicação do alta frequência. A escolha da mesma vai depender do tipo de pele do paciente, por exemplo, as peles mais sensíveis devem receber uma máscara calmante, as oleosas, uma que ajude no controle da oleosidade, as desidratadas uma hidratante. Ressalta-se também o uso de máscaras de argila, máscaras nutritivas, máscaras clareadoras e máscaras firmantes. A mesma deve ser utilizada de acordo com a indicação do fabricante ${ }^{8,11,13}$.

\section{Aplicação do Filtro de Proteção Solar}

Para finalizar o procedimento, é aplicado protetor solar com fator de proteção acima de 30 (FPS) e PPD (Persistent Pigmented Darkening) acima de 12 o qual protege a pele contra os raios ultravioleta A (UVA), para manter a pele protegida, evitando manchas e queimaduras solares. Recomenda-se também o uso diário do protetor solar na rotina diária, devendo ser reaplicado a cada 3 horas $s^{8,11,13}$.

\section{Benefícios da Limpeza de Pele no combate à Acne}

O tratamento da acne baseia-se no princípio do controle dos fatores que constituem sua patogenia, buscando assim: reduzir a produção sebácea e a queratinização folicular, diminuir a intensidade de colonização, principalmente, por Propionibacterium acnes e cessar a inflamação ${ }^{10,14}$.

A limpeza da pele com acne deve ser realizada, uma vez ao dia, de forma suave, com sabões ou antissépticos adequados. Toalhas e esponjas devem ser evitadas, pois podem aumentar a irritação no local. A lavagem exagerada e o uso contínuo de esfoliantes devem ser evitados, pois causam a ruptura dos folículos e podem aumentar a inflamação ${ }^{10,11,15}$.

A higienização da pele no paciente com acneenvolve várias considerações, incluindo combinar o tipo de pele com o tipo adequado de cosmético, métodos de limpeza ideais que não ocasionam lesões na pele e irritação/inflamação, tratamento de partes do corpo que não seja apenas o rosto e as percepções do paciente sobre a causa e o tratamento da acne. A hidratação da pele evita e alivia a irritação cutânea, acalmando a pele ao diminuir a evaporação da água ${ }^{15,16}$. 
Alguns dos benefícios da higienização profunda da pele são a promoção do reequilíbrio do $\mathrm{pH}$ cutâneo, restabelecer a integridade do manto hidrolipídico, controlar a oleosidade e processos acneicos infecciosos (tratamento coadjuvante para acne), remoção de conteúdos teciduais inestéticos (comedões e pústulas), melhorar a lubrificação e atuar na renovação celular ${ }^{5,0,11}$.

As condutas estéticas para o tratamento da acne são diversificadas e a sua seleção dependerá, principalmente, do grau de gravidade da acne. É bom destacar que os profissionais da área da estética podem atuar sem supervisão médica não casos de acnes graus I e ll, mas em casos mais graves só poderá atender sob orientação e/ou supervisão médica ${ }^{6,11}$.

O protocolo estético de limpeza de pele facial é fundamental para estimular a renovação celular, rejuvenescimento facial, controle da oleosidade, clareamento da pele, eliminação cravos e milliuns, otimizando a homogeneidade da coloração, melhora da oxigenação local, proporcionando aspecto mais jovial da pele ${ }^{6,11}$. O quadro 1 apresenta os principais benefício da limpeza de pele no tratamento da acne vulgar.

Quadro 1. Principais benefícios da limpeza de pele no tratamento coadjuvante da acne vulgar

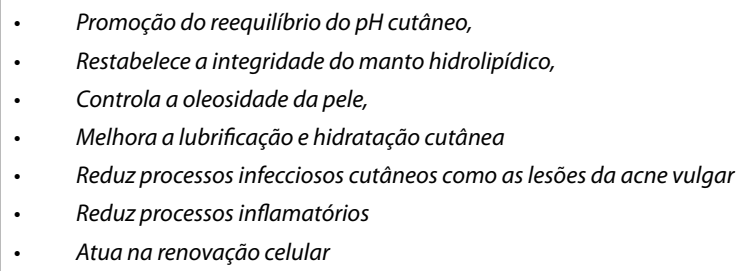

Fonte: Draelos, 20055; Borges \& Scorza, 20166; Draelos, 20187; Dal Gobbo, 201011; Goodman 200916.

\section{Contraindicações da Limpeza de Pele}

A limpeza profunda de pele é um procedimento ambulatorial seguro, entretanto, existem algumas contraindicações relativas. As principais contraindicações estão apresentadas no quadro 2.
Quadro 2. Principais contraindicações relativas da limpeza de pele

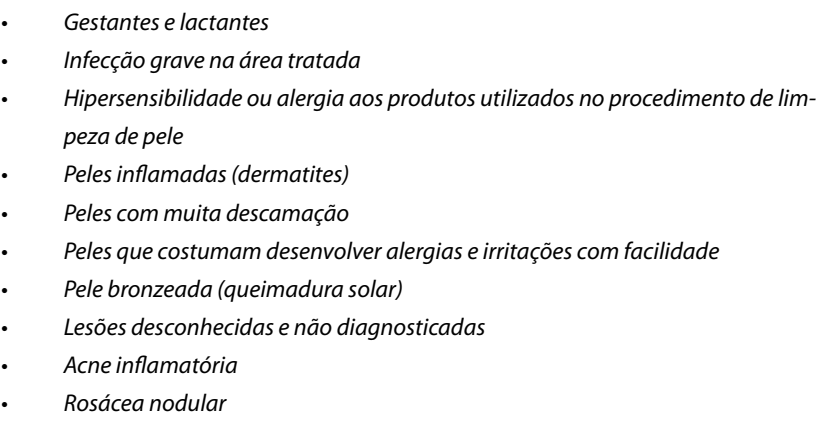

Fonte: Borges \& Scorza, 20166; Dal Gobbo, 201011; Goodman 200916.

\section{Prevenção da Acne}

Algumas orientações podem ser feitas pelo profissional da estética ao cliente para evitar complicações da acne. O cliente não deve manipular as lesões (espremer), pois corre o risco de infectar, inflamar ou deixar cicatrizes. Além de ser recomendado usar produto cosmético de higiene para pele acneica ou oleosa, todavia a limpeza excessiva pode ser prejudicial à pele, pois pode causar irritação ou agravar as lesões. A acne pode melhorar quando a pessoa é exposta moderadamente ao sol, porém a exposição excessiva tende a piorar o quadro. De qualquer forma, o uso protetor solar é um procedimento fundamental ${ }^{11,16}$.

O indivíduo que apresenta acne vulgar deve ser aconselhado a lavar e secar suavemente a região corporal afetada, uma vez ao dia, com agente de limpeza próprio e suave. Devido ao efeito irritativo da terapêutica, devem-se usar cremes ou emulsões sem óleo, sendo fundamental evitar manipulação das lesões ${ }^{10}$.

Há diversos cosméticos que podem ser utilizados para controlar a oleosidade e tratar a pele acneica. Uma boa proposta de tratamento pode ser o emprego de um sabonete normalizador; uma loção tônica adstringente; máscara para controle da oleosidade, secativa, anti-inflamatória e cicatrizante; um sérum secativo ou oil control; e um bom fotoprotetor. Convém ressaltar que o ideal seria o paciente passar por uma avaliação com dermatologista para a prescrição adequada de cosméticos ou medicamentos para o seu tipo de lesão acneica ${ }^{10,11,15,16}$.

Para se obter bons resultados no tratamento da acne, os pacientes precisam ser educados em termos familiares e encorajados a promover boas práticas de cuidado da pele ao longo da vida. Os pacientes devem ser instruídos a limpar corretamente, hidratar e proteger a pele de danos ambientais e deve receber tratamento dermatológico, se necessário $0^{10,16}$. 


\section{Conclusão}

A higiene adequada, hidratação e proteção da pele são de suma importância não só no que se diz respeito ao embelezamento corporal, mas também para a saúde e prevenção da acne vulgar. Recomenda-se que a limpeza facial deve ser efetuada uma vez por dia, com agente de limpeza ajustado ao tipo de pele, como preparação para a aplicação dos tratamentos posteriores. Devido ao efeito irritativo do tratamento farmacológico da acne vulgar, devem-se usar cremes ou emulsões sem óleo, sendo fundamental evitar manipulação das lesões.

O protocolo de uma limpeza de pele profunda deve ser específico para cada indivíduo para obter satisfação e eficiência no tratamento. A limpeza profunda de pele deve ser realizada respeitando-se o ciclo de renovação celular a cada 28 dias. Este protocolo estético facial é fundamental para estimular a renovação celular, rejuvenescimento facial, controle da oleosidade, clareamento da pele, eliminação cravos e milliuns, otimizando a homogeneidade da coloração, melhora da oxigenação tecidual local, proporcionando aspecto mais jovial da pele.

Um algoritmo sobre a limpeza, hidratação e proteção da pele, elaborado por dermatologistas, pode ser uma ferramenta útil para atender às necessidades individuais de cuidados com a pele de pacientes com acne e garantir o regime mais benéfico deste tratamento coadjuvante da acne de forma individualizada para os pacientes.

Conhecimentos científicos sobre mecanismos envolvidos na manutenção fisiológica da pele, bem como daquelas que a desregulam são fundamentais para entendimento dos produtos que estão sendo utilizados no mercado e incentivar pesquisas para melhorias e inovações. Destaca-se também a importância de a orientação profissional para o método tornar-se eficaz e saudável.

\section{Referências}

1. Borges FS. Dermatofuncional: modalidades terapêuticas nas disfunções estéticas. 2 ed., São Paulo: Phorte; 2010.

2. Maio M.Tratado de Medicina Estética. 2. ed., São Paulo: Roca; 2011.

3. Kede MPV, Sabatovich O. Dermatologia Estética. 3. ed., São Paulo: Atheneu; 2015.

4. Al-Talib H, Al-Khateeb A, Hameed A, Murugaiah C. Efficacy and safety of superficial chemical peeling in treatment of active acne vulgaris. An Bras Dermatol. 2017;92(2):212-6.

5. Draelos ZD. Procedimentos em dermatologia cosmética: cosmecêuticos. Rio de Janeiro: Elsevier; 2005.
6. Borges FS, Scorza FA. Terapêutica em estética - conceitos e técnicas. Phorte Editora, p. 584, 2016.

7. Draelos ZD. The science behind skin care: Cleansers. J Cosmet Dermatol. 2018;17(1):8-14.

8. Periotto DK. Cosmetologia Aplicada: Princípios básico. $\mathrm{SL}, 2008$.

9. Araújo LD, Brito JQA. Uso do Pelling químico no tratamento da acne grau II: Revisão Sistemática. Id on Line Multidisciplinary and Psycology Journal, Vitória da Conquista. 2017; 11(35):100-15.

10. Figueiredo A, Massa A, Picoto A, Soares AP, Basto AS, Campos $\mathrm{CR}$, et al. Avaliação e tratamento do doente com acne - Parte II: Tratamento tópico, sistêmico e cirúrgico, tratamento da acne na grávida, algoritmo terapêutico. Rev Port Clin Geral. 2011;27:66-76.

11. Dal Gobbo P. Estética facial essencial: orientação para o profissional da estética. São Paulo-SP, Atheneu, 2010.

12. Fasih $S$, Arif AB. Salicylic acid peeling in the treatment of Facial acne vulgaris. Pak J Physiol. 2016;12(4):1-9.

13. Oliveira AL, Perez E. Estética facial: curso didático de estética. vol. 2. São Caetano do Sul, SP: Yendis, 2008.

14. Costa A, Lage $D$, Moisés TA. Acne e dieta: verdade ou mito? [revisão]. An. Bras. Dermatol. 2010;85(3):346-53.

15. Herane MI. Actualización terapéutica en acne vulgaris. Dermatol Pediatr Lat. 2005;3(1):5-19.

16. Goodman G. Cleansing and moisturizing in acne patients. Am J Clin Dermatol. 2009;10 Suppl 1:1-6. 